\title{
A smoking cessation intervention in a paediatric clinic setting reduced smoking in low income women
}

\author{
Curry SJ, Ludman EJ, Graham E, et al. Pediatric-based smoking cessation intervention for low-income women: a \\ randomized trial.Arch Pediatr Adolesc Med 2003;157:295-302.
}

\section{QUESTION: How effective is a smoking cessation intervention for women in low income families who are bringing their children to a paediatric clinic?}

\section{Design}

Randomised (allocation unconcealed*), unblinded,* controlled trial with 12 months of follow up.

\section{Setting}

4 clinics in Seattle, Washington, USA.

\section{Participants}

303 women $>18$ years of age (mean age 34 y) who identified themselves as smokers, brought their children to 1 of the 4 paediatric clinics, had no plans to move from the Seattle area in the next 4 months, and provided a telephone contact number. 12 month follow up was $81 \%$.

\section{Intervention}

Women were allocated to a smoking cessation intervention $(n=156)$ or usual care $(n=147)$. The intervention involved a brief motivational message from the clinician that emphasised the harm to children from smoking, a self help guide to quitting smoking, a motivational interview with a clinic nurse or study interventionist during the scheduled clinic visit, and up to 3 outreach telephone counselling calls from the nurse or interventionist during the 3 months after the clinic visit.

\section{Main outcome measures}

Self reported smoking abstinence rates for $\geq 7$ days (prevalent abstinence). Secondary outcomes were rates of attempts to quit, abstinence for $\geq 24$ hours, and continuous abstinence between 3 and 12 months.

\section{Main results}

Analysis was by intention to treat. More women in the intervention group than the usual care group reported abstinence at 12 months but not at 3 months (table). The groups did not differ for attempts to quit, abstinence for

Source of funding: National Heart, Lung and Blood Institute.

For correspondence: Dr S J Curry,

University of Illinois at Chicago, Chicago, IL,

USA.suecurry@uic.edu

\section{$\geq 24$ hours, or continuous abstinence.}

\section{Conclusion}

Among women in low income families, a smoking cessation intervention received from their children's paediatric clinic reduced smoking at 1 year.

*See glossary.

\section{COMMENTARY}

The US Public Health Service Guideline on Treating tobacco use and dependence ${ }^{1}$ gives clear recommendations to clinicians in paediatric settings to intervene with parents to limit children's exposure to second hand smoke.

While earlier trials have shown promising short term efficacy, this well designed study by Curry $e t a l$ is the first to show evidence for long term abstinence after a brief, paediatric office based, tobacco cessation intervention.

With regards to generalisability, the use of clinic resources was minimal, requiring only brief provider advice ( $1-5 \mathrm{~min})$ and nursing time for the follow up telephone calls. Although all participants also received a small financial incentive, it is not clear whether this could have enhanced the effectiveness. ${ }^{2}$ The study involved some training (provider: $15 \mathrm{~min}$, nurse: $8 \mathrm{~h}$ ). The 3 sessions of telephone counselling are analogous to many effective tobacco quit lines that are in existence today in the US and elsewhere. ${ }^{3}$ The results of this study are consistent with other low to moderate intensity tobacco cessation interventions, ${ }^{1}$ which is important, considering the population studied.

An accompanying editorial ${ }^{4}$ raises important questions about the boundary that exists between caring for children and parents, and also lists many well known barriers to delivery of preventive services. Despite these caveats, this study is very promising. The intervention, which "off loads" clinicians by delegating most of the effort to telephone counsellors, was well received and fairly easy to implement, and is currently available to most providers.

Paediatricians would do well to take notice, and all clinicians should consider implementing a systematic approach to identifying parents who smoke, briefly intervening, and referring them to telephone tobacco cessation counselling.

Charles J Bentz, MD, FACP Medical Director: Tobacco Cessation and Prevention Providence Health System, Oregon, USA

1 Fiore MC, Bailey WC, Cohen SJ, et al. Treating tobacco use and dependence. Clinical Practice Guideline. Rockville, MD: US Department of Health and Human Services, June 2000. http://hstat.nlm.nih.gov/

2 The use and impact of incentives in population-based smoking cessation programs: a review [abstract 122934]. Database of Abstracts of Reviews of Effects, available http:// nhscrd.york.ac.uk/welcome.htm

3 Stead LF, Lancaster T, Perera R. Telephone counselling for smoking cessation. Cochrane Database Syst Rev 2002;(2):CD002850.

4 Berman S. Caring for parents vs caring for children: is there a difference? [editorial]. Arch Pediatr Adolesc Med 2003;157:221-2

Smoking cessation intervention v usual care delivered to low income women attending a paediatric clinic with their childrent

\begin{tabular}{lclll} 
Outcomes & Intervention & Usual care & RBI (95\% Cl) & NNT (Cl) \\
Prevalent abstinence at 3 months & $7.7 \%$ & $3.4 \%$ & $129 \%(-15$ to 534$)$ & Not significant \\
\hline Prevalent abstinence at 12 months & $13.5 \%$ & $6.9 \%$ & $147 \%(22$ to 376$)$ & $10(4$ to 66$)$ \\
\hline
\end{tabular}

†Prevalent abstinence was self reported smoking abstinence rates for $\geq 7$ days. Abbreviations defined in glossary; RBI, NNT, and Cl calculated from odds ratio in article (adjusted for smoking within 15 minutes of waking and quitting for $\geq 6$ months previously). 